\title{
Model of ELID Grinding Material Removal Rate
}

\author{
Ji-Cai KUAI \\ School of Mechanical and Power Engineering, Henan Polytechnic University, Jiaozuo, Henan, China \\ hitgjc@163.com
}

Keywords: ELID Grinding, Material Removal Rate, Model.

\begin{abstract}
This paper studies the model of ELID grinding material removal rate, proposes a new model of material removal rate and then conducts theoretical analysis and experimental verification. Studies show that the theoretical calculation results of the model and the actual measurement results are in good agreement, demonstrating the regularity of material removal in ELID grinding process, which is qualified with a clear theoretical significance and application value.
\end{abstract}

\section{Introduction}

ELID grinding is an ultra-precision grinding method with broad application, and the oxidation film with rich water, low hardness and good elasticity bears the abrasive particles' grinding and polishing on the ultra-precision grinding surface, making ELID grinding process and polishing process have very similar material removal process [1].

Preston equation is widely applied in the field of grinding and polishing [2]. Based on the original Preston equation, combined with the characteristics of the mechanical properties of ELID grinding oxidation film, this paper makes an expansion for Preston equation, proposes a new model of ELID grinding material removal rate, further conducts theoretical analysis and calculation and conducts experimental verification.

\section{Model of ELID Grinding Material Removal Rate}

Malkin, et al think that the grinding force is caused by cutting and rubbing, so the cutting force of single abrasive particle can be expressed as the combination of the part caused by cutting and the part caused by rubbing [3]. The cutting force caused by rubbing is related to the contact pressure, the contact area and the friction coefficient between abrasive particles and workpiece.

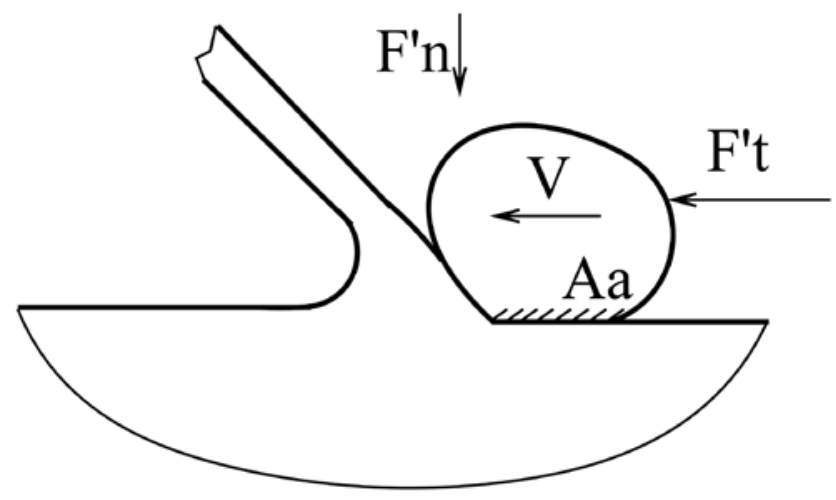

Fig. 1. Grinding Model

Assuming the abrasive particle is globular, as is shown in Fig.1, it can be know from contact mechanics that the contact circle radius of abrasive particles and the workpiece can be expressed as:

$$
r=\left(\frac{3 F R}{4 E}\right)^{1 / 3}
$$


In the formula, $r$ : contact circle radius, $R$ : radius of abrasive particle, $F$ :bearing normal load of abrasive particle, $E$ : elastic modulus.

In ELID grinding, because the abrasive particles are coated with oxidation film, the grinding process is not simple cutting of abrasive particles, while the oxidation film of grinding wheel is actually carrying the abrasive particles to conduct cutting. Therefore, the elastic modulus herein should be defined as the composite value of the elastic modulus of oxidation film and the elastic modulus of abrasive particles [4].

Contact area between abrasive particle and workpiece:

$$
A_{\mathrm{a}}=\pi r^{2}
$$

Tangential cutting force of single abrasive particle [3]:

$$
F_{\mathrm{t}}^{\mathrm{v}}=F_{\mathrm{tc}}+\mu P A_{\mathrm{a}}
$$

In the formula, Ftc: tangential force caused by cutting; $\mu$ : friction coefficient; P: grinding zone pressure; Aa: contact area.

Normal cutting force of single abrasive particle:

$$
F_{\mathrm{n}}^{x}=F_{\mathrm{nc}}+P A_{\mathrm{a}}
$$

In the formula, $F_{\mathrm{nc}}$ : normal force caused by cutting;

Contact arc length between grinding wheel and workpiece:

$$
l_{c}=\left(a d_{g}\right)^{1 / 2}
$$

In the formula: $l_{\mathrm{c}}$ : contact arc length; $a$ : grinding depth; $d_{\mathrm{s}}$ : grinding wheel diameter Therefore, the cutting area of grinding wheel is:

$$
A_{\mathrm{c}}=l_{\mathrm{c}} b
$$

In the formula, $A_{c}$ : cutting area; $b$ : cutting width

If we assume that the contact area of abrasive particle accounts for a certain percentage A of cutting area, namely:

$$
A_{\mathrm{a}}=A A_{\mathrm{c}}=A l_{\mathrm{c}} b
$$

In the formula, $A$ : abrasion rate of grinding particle.

Substituting Formula 7) into Formula 4), getting the derivative of $A$, and the grinding zone pressure after organizing is:

$$
P=\frac{d F_{n}^{0} / d A}{A_{c}^{b}}
$$

Through Preston's Equation [2], the material removal rate of the $i$-th abrasive particle on the surface of grinding wheel can be expressed as:

$$
u_{\mathrm{i}}=K P_{\mathrm{i}} V_{s \mathrm{i}}
$$

In the formula, $u_{\mathrm{i}}$ : the material removal rate of the $i$-th abrasive particle; $K$ : Preston coefficient; $P_{\mathrm{i}}$ : pressure of the $i$-th abrasive particle; $V_{\mathrm{si}}$ : grinding speed of the $i$-th abrasive particle.

Substituting Formula 8) into Formula 9): 


$$
u_{i}=K \frac{d E_{n i}^{i} / d A i}{u_{c}^{b} b} V_{s i}
$$

Formula 10) is the material removal rate model of individual particle of ELID grinding, and the model shows that the increase in grinding arc length and grinding width will result in the decrease of contact pressure, making the material removal rate decrease; increase of grinding speed will significantly increase the grinding efficiency, making the material removal rate increase. If Formula 10) takes area integral on the whole grinding zone, the material removal rate model of wheel grinding zone of ELID grinding can be obtained:

$$
U=\int_{x_{1}}^{x_{2}} \int_{y_{1}}^{y_{2}} u_{i}(x, y) d x d y
$$

Since the actual completed material removes the abrasive particles involved in cutting, Formula 11) is only a rough calculation method of material removal rate. Accurate material removal rate model should be obtained through the accumulation of the removal rate of every abrasive particle involved in cutting.

Under the effect of grinding heat generated in ELID grinding process, the composition of the oxidation film on the surface of iron-based wheel surface changes, generating $\alpha-\mathrm{Fe}_{2} \mathrm{O}_{3}$ of particle size in the nanoscale which covers around the diamond particles [5,6], and forming composite abrasive particles centering on the diamond abrasive particles surrounded by $\alpha-\mathrm{Fe}_{2} \mathrm{O}_{3}$, thus the number of particles that actually participate in cutting should be equal to the sum of diamond abrasive particles and $\alpha-\mathrm{Fe}_{2} \mathrm{O}_{3}$ abrasive particles generated after change. This number should be much larger than the number of diamond abrasive particles in traditional grinding. Because of this, the calculation in this case uses the number of particles theoretically involved in cutting, rather than the number of particles actually involved in cutting.

Particle number per unit area of abrasive wheel surface:

$$
G_{0}=\frac{6 V_{B}}{\pi d_{g}^{2}}
$$

In the formula, $G_{0}$ : particle number per unit area; $V_{\mathrm{g}}$ : the volume ratio of abrasive particles in grinding wheel; $d_{\mathrm{g}}$ : diameter of abrasive particle.

The number of abrasive particles participating in cutting:

$$
n_{\mathrm{c}}=G_{0} A_{\mathrm{c}}
$$

In the formula, $n_{\mathrm{c}}$ : the number of abrasive particles participating in cutting.

Or the accumulation of the removal rate of each abrasive particle can obtain the material removal rate model of all the abrasive particles participating in the cutting:

$$
U^{\prime}=\sum_{i=0}^{n_{c}} u_{i}
$$

To simplify the calculations, it can be assumed that the diameter of the abrasive particles on the surface of grinding wheel and the edge height are the same, and also are well-distributed, therefore the material removal rate of each abrasive particle is approximately regarded as equal, namely: $u_{1}=u_{2}=\ldots . .=u_{\mathrm{nc}}=u$, and from Formula 10) and 12), there are:

$$
U^{n}=n_{e} u=G_{0} K\left(d F_{n}^{\prime} / d A\right) V_{s}
$$

Formula 15) is the material removal rate model of all the abrasive particles participating in cutting after simplified calculation. 


\section{ELID Grinding Experiment}

\section{Experimental Equipments}

Experimental equipment: ELID grinding machine MM7120; grinding wheel: W40 iron-based diamond grinding wheel; specifications: $\Phi 200 \times 10 \mathrm{~mm}$; ELID grinding power: HDMD-3 type high-frequency DC - pulse power; self-developed electrolytic grinding liquid; detection equipment: KISTLER dynamometer, electronic scale with the precision of $0.5 \mathrm{mg}$; material for test: applying nano $\mathrm{ZrO}_{2}$ developed by School of Materials of Harbin Institute of Technology.

\section{Experimental Parameters}

They are shown in Table 1.

Tab. 1 ELID grinding process parameters

\begin{tabular}{|c|c|c|c|c|c|}
\hline Speed $(\mathrm{r} / \mathrm{min})$ & Feed rate(m/min) & Cutting depth(mm) & Voltage(V) & Current(A) & Pulse width $(\mu \mathrm{s})$ \\
\hline 1500 & 7.2 & $0.002-0.02$ & 120 & $2-5$ & 20 \\
\hline
\end{tabular}

\section{Experimental Methods}

First grinding force needs to be actually measured, while coolant filtration device is placed in the machine table to collect the chips. Using the measured grinding force, the theoretical data of material removal rate can be calculated according to the model, the actual data of ELID grinding material removal rate can be obtained by using the actual chip collected, and finally the theoretical data and actual data are analyzed.

\section{Experimental Results}

They are shown in Table 2.

Tab. 2 Experimental results of grinding force and material removal rate

\begin{tabular}{|c|c|c|c|c|}
\hline Grinding depth $(\mathrm{mm})$ & 0.005 & 0.01 & 0.015 & 0.02 \\
\hline Tangential grinding force $(\mathrm{N})$ & 10 & 22 & 29 & 34 \\
\hline Normal grinding force $(\mathrm{N})$ & 50 & 114 & 165 & 230 \\
\hline Material removal rate $(\mu \mathrm{m} / \mathrm{min})$ & 5.25 & 5.74 & 6.27 & 6.66 \\
\hline
\end{tabular}

\section{Discussion and Analysis}

Fig. 2 is the comparison between the theoretical calculation results and experimental results of ELID grinding material removal rate model. It can be seen from Fig.2 that the experimental results and the theoretical calculation results agree well, the error is about $11 \%$, and the theoretical calculation results are smaller than the actual measurements. This is probably because the actual measurements can hardly totally accord with the theoretical calculation conditions; secondly, the grinding wheel will consume and disperse in chips in the actual ELID grinding process; although the chips are on sorting, some deciduous particles and binding doping may mingle in the chips, and increases the weight of the chips.

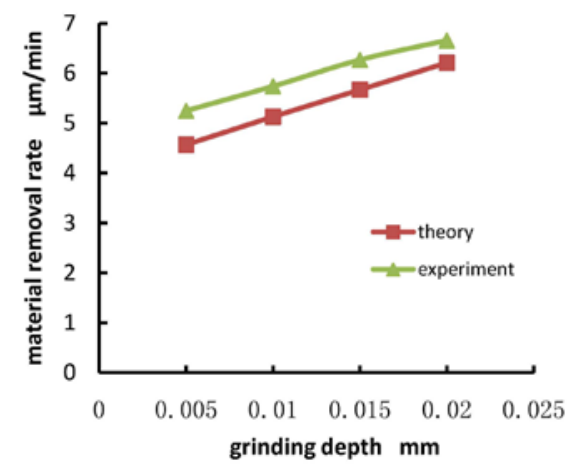

Fig. 2 Theoretical calculation results and experimental results of ELID grinding material removal rate model 


\section{Summary}

1. Proposing a new ELID grinding material removal rate model;

2. Theoretical calculation results and experimental results of the model are in good agreement;

3. The model can express the regularity of ELID grinding material removal, and has good application value.

\section{Acknowledgement}

The authors wish to thank the helpful comments and suggestions from my teachers of Harbin Institute of Technology. This project is supported by the National Natural Science Foundation of China (Grant No.51475147) and the key project of science and technology of Educational Commission of Henan Province of China(Grant No.13A460341).

\section{References}

[1] J.C. Kuai, Friction coefficient of nano-ceramic polished by oxide film on elid grinding wheel, Advanced Materials Research. 669 (2013) 91-94.

[2] W.L. Zhang. H.Y. Jin, Research on digital simulation and experiment of removal function of bonnet tool polishing, Journal of Mechanical Engineering. 45 (2009):308-312.

[3] S. Malkin, Grinding Technology Theory And Application Of Machining With Abrasives, 1 edition, Prentice Hall, New York, 1989.

[4] J.C. Kuai. F.H. Zhang. Y. Zhang, Mechanical properties of oxide film on elid grinding wheel surface, Nanotechnology and Precision Engineering. 8(2010):447-451.

[5] J.C. KUAI, Adhesion model and shedding limit's identification of the oxide film on The surface of elid grinding wheel, Advanced Materials Research. 900 (2014):557-560.

[6] J.C. Kuai, Discovery of $\alpha$-Fe2O3 in the oxide film on ELID grinding wheel, Advanced Materials Research. 1061-1062(2015): 446-449. 